\title{
The epidemiology of gastrointestinal cancer
}

The proportion of patients with gastric cancer who are cured of their disease is so small that the epidemiologist can, with reasonable safety, regard death rates and incidence rates as almost synonymous. Straightforward attempts at improving therapeutic efficiency have been so unsuccessful ${ }^{1}$ that there is a strong and perhaps unassailable case for a change in emphasis to the investigation of the cause of the disease, for an increased understanding of its aetiology should lead naturally to effective preventive measures. A striking difficulty of the epidemiological approach is, however, the lack of a testable hypothesis which can be based upon what seems at first to be a generous amount of knowledge.

Gastric cancer varies greatly in incidence in different parts of the world, ${ }^{2,3,4}$ being uncommon in the U.S.A., though probably rarer in many parts of Africa, common in Japan, and in Europe, an area of intermediate incidence, it shows a reasonably steady gradation of decreasing frequency from east to west. But even within national areas further fluctuations occur, such as the high gastric cancer incidence in north Wales. ${ }^{5,6}$ These patterns are likely to be due mainly to environmental rather than genetic factors, one reason for this view being that the incidence of gastric cancer tends to fall in migrants from high-risk to low-risk areas, such as from Japan to the U.S.A. ${ }^{7,8,9}$

Within geographical areas gastric cancer incidence rates can vary with time, perhaps the most striking change being the falling incidence of gastric cancer in the U.S.A., though similar variations are also occurring elsewhere.

Dietary carcinogens would seem to be the most likely causal factors, but searches for such substances have been uniformly disappointing. One reason has undoubtedly been the difficulty which any individual has in remembering the constituents of a diet taken in the past. ${ }^{10}$ It seems possible, and even likely, that the relevant events take place a considerable number of years before any tumour is apparent histologically. A parallel situation is probably that in lung cancer: smokers who cease smoking continue for some years to have an increased risk of carcinoma compared with non-smokers although the chances are less than those for comparable individuals who continue to smoke. ${ }^{11}$ The lack of suitable experimental models for human gastric cancer has also been a considerable problem. Very few substances are known which can be shown experimentally to induce the appearance of gastric adenocarcinomata. One such is aflatoxin, ${ }^{12}$ which can be formed by Aspergillus growing on a surprisingly wide variety of carbohydrate foods, including potatoes, wheat and rice, and groundnuts. ${ }^{13}$ There is, however, no evidence that aflatoxin is a significant cause of gastric neoplasia in man.

The raised incidence of gastric cancer amongst the poorer members of European and north American populations ${ }^{14}$ could be explained by a variety of factors, such as the constant re-use of cooking fats which come to contain carcinogenic hydrocarbons, or by lower standards of food preservation which lead to adulteration by moulds or bacteria which form carcinogens. There is, however, no direct evidence in favour of these or any other similar speculative hypotheses.

The genetic component in liability to gastric cancer, though weak, is important as it offers a different approach to the investigation of the disease. The association of gastric cancer with blood group $\mathrm{A}^{15}$ has been found repeatedly throughout the world in both high and low incidence areas, ${ }^{16}$ and its reality is emphasized by further blood group A associations with liability to pernicious anaemia ${ }^{17}$ and to salivary tumours. ${ }^{18,19}$ The $\mathrm{ABO}(\mathrm{H})$ blood group substances are present in large quantities in the mucosal epithelium, ${ }^{20,21}$ but the lack of any obvious physiological role has hindered further study. The description of an association between the appearance of intestinal alkaline phosphatase in the serum and blood groups $O$ and $\mathrm{B}^{22,23,24}$, i.e., those apparently relatively insusceptible to gastric cancer, which seems in some way to be induced by the feeding of fat, ${ }^{25}$ does go some way in relating blood groups to alimentary function. It seems unlikely, however, that the 
inherited influence on gastric cancer incidence can be related more closely to intestinal phosphatase than to the blood groups, for ABH non-secretion seems to inhibit the appearance of intestinal phosphatase in the serum much more completely than blood group A, yet gastric cancer probably appears very slightly, if at all, more frequently than might be expected in ABH non-secretors. ${ }^{16}$

The epidemiological picture of colonic and rectal cancer is, if anything, more obscure than that of gastric cancer. Colonic cancer frequency seems to be inversely related to that of gastric cancer: it tends to be common where gastric cancer is rare, to affect women more often than men, and perhaps to be rising in incidence in countries like the U.S.A. ${ }^{26,27,25}$, where gastric cancer incidence is falling. The customary division between colonic and rectal cancer at the rectosigmoid junction, an area of high cancer incidence, allows differences between the two regions to be obscured by small variations in methods of classification. Rectal cancer, however, does seem to affect men more often than women though this seems to be due in fact to a male predominance with increasing age, the sex ratio changing from 1:1 at age 40 years to about $2: 1$ at age 65 years. ${ }^{29}$ This pattern could reflect a greater male exposure or susceptibility to carcinogenic activity, but we have almost no knowledge of the factors which could be involved. The tendency for carcinomata to occur in the caecum, sigmoid, and rectum, areas where faecal stasis tends to occur, suggests a contact factor, which is supported to some extent by the probable low incidence of large bowel cancer in Africans taking a high residue diet. However, it is not known whether large bowel cancer is due to an ingested carcinogen or to a metabolic byproduct of a normal diet.

Environmental factors must predominate as influences on the incidence of large intestinal cancer as for gastric cancer, and again migrant studies give some of the best evidence to support this view. ${ }^{7,8,9}$ Death rates from arteriosclerotic heart disease and from colonic cancer seem to be related to each other in individual countries (Wynder, E. L., personal communication), but it seems likely that this association is due to some other factor common to both.

It is understandable that the epidemiology of gastrointestinal cancer has been an unpopular subject for the short-term rewards have been slight. However, the size of the problem does mean that small advances, though unexciting, can be valuable for their wide potential application.

M. J. S. LANGMAN

\section{REFERENCES}

${ }^{1}$ Brooks, V. S., Waterhouse, J. A. H., and Powell, D. J. (1965). Carcinoma of the stomach: a 10-year survey of results and of factors affecting prognosis. Brit. med. J., 1, 1577-1583.

'World Health Organization (1965). Epidem. vital Statist. Rep., 18, 261-288.

'Segi, M., and Kurihara, H. (1966). Cancer Mortality for Selected Sites in 24 Countries, No. 4 (1962-1963). Department of Public Health, Tohoku University School of Medicine, Sendai.

'Doll, R., Payne, P., and Waterhouse, J. (1966). Cancer Incidence in Five Continents. International Union against Cancer. Springer, Berlin.

sStocks, P. (1950). Cancer of the stomach in the large towns of England and Wales, 1921-1939. Brit. J. Cancer, 4, 147-157.

'Legon, C. D. (1951). A note on geographical variations in cancer mortality with special reference to gastric cancer in Wales. Ibid., 5, 175-179.

'Smith, R. L. (1956). Recorded and expected mortality among the Japanese of the United States and Hawaii with special reference to cancer.

J. nat. Cancer Inst., 17, 459-473.

'Haenszel, W. (1961). Cancer mortality among the foreign-born in the United States. Ibid., 26, 37-132.

'Buell, P., and Dunn, J. E., Jr. (1965). Cancer mortality among Japanese Issei and Nisei of California. Cancer (Philad.), 18, 656-664.

${ }^{10}$ Acheson, E. D., and Doll, R. (1964). Dietary factors in carcinoma of the stomach. Gut, 5, 126-131.

"Doll, R., and Hill, A. B. (1964). Mortality in relation to smoking: ten years' observations of British doctors. Brit. med. J., 1, 1399-1410.

${ }^{12 B u t l e r, ~ W . ~ H ., ~ a n d ~ B a r n e s, ~ J . ~ M . ~(1966) . ~ C a r c i n o m a ~ o f ~ t h e ~ g l a n d u l a r ~ s t o m a c h ~ i n ~ r a t s ~ g i v e n ~ d i e t s ~ c o n t a i n i n g ~ a f l a t o x i n . ~ N a t u r e ~(L o n d .), ~ 209, ~} 90$.

${ }^{12}$ Hesseltine, C. W., Shotwell, O. L., Ellis, J. J., and Stubblefield, R. D. (1966). Aflatoxin formation by Aspergillus flavus. Bact. Rev., 30, 795-805.

${ }^{16}$ Registrar General for England and Wales (1954). Decennial Supplement 1951 : Occupational mortality, Part I, Table IIA. H.M.S.O., London.

${ }_{15}$ Aird, I., Bentall, H. H., and Roberts, J. A. F. (1953). A relationship between cancer of the stomach and the ABO blood groups. Brit. med. J.,

1, 799-801.

${ }^{10}$ McConnell, R. B. (1966). The Genetics of Gastro-intestinal Disorders. Oxford University Press, London.

${ }^{17 B r i t . ~ M e d . ~ J . ~(1956) . ~ A n ~ a s s o c i a t i o n ~ b e t w e e n ~ b l o o d ~ g r o u p ~ A ~ a n d ~ p e r n i c i o u s ~ a n a e m i a ~: ~ a ~ c o l l e c t i v e ~ s e r i e s ~ f r o m ~ a ~ n u m b e r ~ o f ~ c e n t r e s . ~ B r i t . ~ m e d . ~ J ., ~}$ 2, 723-724.

18. Cameron, J. M. (1958). Blood groups in tumours of salivary tissue. Lancet, 1, 239-240.

${ }^{10}$ Osborne, R. H., and De George, F. V. (1962). The ABO blood groups in parotid and submaxillary gland tumors. Amer. J. hum. Genet., 14, 199-209.

${ }^{20}$ Glynn, L. E., and Holborow, E. J. (1959). Distribution of blood-group substances in human tissues. Brit, med. Bull., 15, $150-153$.

${ }^{21}$ Szulman, A. E. (1962). The histological distribution of the blood group substances in man as disclosed by immunofluorescence. II. The $\mathrm{H}$ antigen and its relation to A and B antigens. J. exp. Med., 115, 977-996.

"Arfors, K. E., Beckman, L., and Lundin, L. G. (1963). Genetic variations of human serum phosphatases. Acta genet. (Basel), 13, 89-94.

22Shreffler, D. C. (1965). Genetic studies of blood group-associated variations in a human serum alkaline phosphatase. Amer. J. hum. Genet., 17, 71-86. 
${ }^{24}$ Bamford, K. F., Harris, H., Luffman, J. E., Robson, E. B., and Cleghorn, T. F. (1965). Serum-alkaline-phosphatase and the ABO bloodgroups. Lancet, 1, 530-531.

${ }^{25}$ Langman, M. J. S., Leuthold, E., Robson, E. B., Harris, J., Luffman, J. E., and Harris, H. (1966). Influence of diet on the intestinal component of serum alkaline phosphatase in people of different $\mathrm{ABO}$ blood groups and secretor status. Nature (Lond.), 212, 41-43.

${ }^{26}$ Griswold, M. H., Wilder, C. S., Cutler, S. J., and Pollack, E. S. (1955). Cancer in Connecticut, 1935-1951. Connecticut State Department of Health, Hartford, Connecticut.

${ }^{27}$ Eisenberg, H. (1962). Cancer in Connecticut, 1960. Connecticut State Department of Health. Hartford, Connecticut.

${ }^{28}$ Ferber, B., Hardy, V. H., Gerhardt, P. R., and Solomon, M. (1962). Cancer in New York State, 1941-1960. Bureau of Cancer Control, New York State Department of Health.

${ }^{20}$ Langman, M. J. S. (1967). Current trends in the epidemiology of cancer of the colon and rectum. Proc. roy. Soc. Med., 60, $210-212$. 